\title{
Analysis of inter-regional effects caused by the wide-area operation of the power grid in Japan: an implication for carbon pricing schemes
}

\author{
Satoshi Nakano ${ }^{1} \cdot$ Ayu Washizu ${ }^{2}$
}

Received: 7 June 2019 / Accepted: 8 March 2020 / Published online: 18 March 2020

(c) The Author(s) 2020

\begin{abstract}
In this research, we examine the socioeconomic impact of carbon pricing (CP) mechanism-related energy policies under the technical constraints of Japan. For this, we have created the Inter-Regional Input-Output Table for a Next Generation Energy System (IONGES) in 2030, considering these technical constraints. Namely, we created three Inter-Regional IONGESs with different assumptions for the widearea operation of the power grid. The results show that the technical constraints of the power grid influence the interregional distribution of renewable energy. Top ten regional renewable energy sectors (TOP10), which has a large production scale, account for approximately $54 \%$ of renewable energy generation, which was found to be biased. From the viewpoint of consumers in each region, we analyzed the share of the electricity cost required to support their consumption. If the $\mathrm{CP}$ mechanism is implemented under the technical constraints of the current power grid, consumers in each region will be impacted unequally. However, it was found that such inequality will be solved under the wide-area operation of the power grid.
\end{abstract}

Keywords Inter-Regional Input-Output Table for a Next Generation Energy System (Inter-Regional IONGES) · Wide-area power grid operation · Renewable energy · Carbon pricing

Ayu Washizu

washizu@waseda.jp

Satoshi Nakano

nakano@jil.go.jp

1 The Japan Institute for Labour Policy and Training, 4-8-23, Kamishakujii, Nerimaku, Tokyo 177-8502, Japan

2 Waseda University, 1-6-1, Nishiwaseda Shinjyuku, Tokyo 169-8050, Japan 


\section{Introduction}

The feed-in tariff (FIT) system introduced to Japan in 2012 was intended to improve the propagation of renewable energy. The FIT purchase of renewable energy has increased by approximately 10 times, from 5.6 TWh in FY 2012 to $57 \mathrm{TWh}$ in FY 2016. However, as Japan's total power generation in FY 2016 was 907.6 TWh, 57 TWh is only $6.3 \%$ of the total. Approximately $60.6 \%$ of the $57 \mathrm{TWh}$ of FITpurchased electricity in 2016 was generated by commercial solar power, $12.5 \%$ by residential solar power, and $10.3 \%$ by wind power. ${ }^{1}$ In Japan, the proportion of solar power generation among renewable energy is high. The increase in variable power sources, such as solar power generation, influences the stability of the Japanese electric power system.

The power demand density per area is higher in Japan than in other countries. In 2015 , the power demand density per area was $0.75 \mathrm{Gwh} / \mathrm{km}^{2}$ in the US and $1.79 \mathrm{Gwh} / \mathrm{km}^{2}$ in Germany, while it was $2.74 \mathrm{Gwh} / \mathrm{km}^{2}$ in Japan. ${ }^{2}$ When the power supply is concentrated in a small area, it is not easy to alleviate fluctuations in the electricity demand and solar power generation, and maintaining system stability becomes difficult. Wide-area operation of electric power systems is one method to solve such problems. In Japan, however, the ten largest power companies supply most of the electricity in their respective jurisdictions, but the power transmission facilities between the grids of each company are not very large. Also, East and West Japan use different AC frequencies $(50 \mathrm{~Hz}$ and $60 \mathrm{~Hz}$ ), rendering wide-area grid operation difficult (Ohashi 2015). While FIT has had certain effects on the introduction of renewable energy in Japan, the technical constraints of power engineering appear to weaken its effects.

In July 2018, the Ministry of the Environment (MOE) of Japan established the "Subcommittee on Utilization of Carbon Pricing". The carbon pricing mechanism is indispensable for promoting the general mitigation of greenhouse gases. Under the above technical constraints, the carbon pricing mechanism should be employed to effectively introduce renewable energy. The purpose of this research is to examine the socioeconomic impacts of carbon pricing mechanism-related energy policies under the technical constraints of introducing renewable energy.

For this, we use input-output analysis, which is an effective method of analyzing socio-economic interdependence based on technology (Leontief 1986). In Japan, the regional division of the electric power system is a technical constraint on the introduction of renewable energy. Therefore, it is necessary to analyze policies, such as the carbon pricing mechanism, from an inter-regional point of view.

\footnotetext{
1 Agency for Natural Resources and Energy (ANRE) Feed-in tariff system information publication website. https://www.enecho.meti.go.jp/category/saving_and_new/saiene/kaitori/index.html (in Japanese, last accessed 2018.08.19).

2 Value calculated using IEA (2017) and UN (2011).
} 


\section{Literature review}

In China, where the government declared the opening of a nationwide carbon market in 2017, the relationship between carbon pricing and the introduction of renewable energy, or that between carbon pricing and the operation of the electric power system, is being researched. Tu et al. (2018) analyzed the effect of carbon pricing on the introduction of wind power, and Tian et al. (2017) developed a model for evaluating the photovoltaic power generation project that considers carbon pricing. Tu and Mo (2017) examined the relationship between carbon pricing and policy for supporting renewable energy, and found that excessive renewable energy subsidization will dilute the policy effectiveness of carbon pricing by reducing the demand for $\mathrm{CO}_{2}$ emission rights. Li et al. (2015) conducted scenario analysis of the effect of carbon pricing on the low carbonization of China's electricity sector using the generation expanding planning model. They found that, if carbon capture and storage (CCS) technology is available, it is possible to achieve a high degree of decarbonization in the power sector by carbon pricing. According to the analytical results of the model developed by Li et al. (2016), the widening of system operation in China increases the amount of introduced renewable energy, but has a limited effect on reducing $\mathrm{CO}_{2}$. This is because, as the electric power system widens, the proportion of inefficient thermal power plants in regions with low fuel prices will be high to secure a dispatchable power supply that is required more as the amount of renewable energy increases. Although Fan and Todorova (2017) stated that China's carbon market is still in an early stage and is not functioning well, the technical constraints on power system operation appear to weaken the effect of the carbon pricing adjustment mechanism. Currently, many researchers in China are conducting model analysis under various technical constraints on methods to construct a low-carbon electric power system by utilizing the recently introduced carbon pricing mechanism (Guo et al. 2017, Ma et al. 2018; Zhao et al. 2018). To increase the introduction of renewable energy in China using the carbon pricing mechanism, new investment to increase the efficiency of thermal power generation as a dispatchable power supply is necessary first.

In many developing countries where electricity is scarce, it is necessary to meet the growing demand for electricity with renewable energy. In those countries, it is also important to appropriately conduct demand-side electricity management. Khan (2018) proposes the implementation of time-varying carbon pricing considering Bangladesh's electric power system.

In countries with mature power supply facilities, the analysis of the effect of carbon pricing is complicated. Gavard (2016) estimated the level of carbon pricing that ensures that wind power generation is cost-effective alongside coal- or gas-fired power generation in Denmark. Through analyzing the effect of carbon pricing up to 2060 in Canada, Lyseng et al. (2016) argued that natural gas power generation is the most cost-effective method, even with the extensive buildout of wind and solar power occurs. Maryniak et al. (2019) stated that it is difficult to develop a low-carbon power supply through the carbon pricing mechanism as 
Fig. 1 Conceptual diagram of an input-output table

\begin{tabular}{|c|c|c|}
\hline & & \\
Intermediate & Final & Total \\
transaction & demand & output \\
$\mathbf{X}=\left(x_{i j}\right)$ & $\mathbf{f}=\left(f_{i}\right)$ & $\mathbf{x}=\left(x_{i}\right)$ \\
& & \\
& & \\
\hline Value added & & \\
$\mathbf{v}^{\prime}=\left(v_{j}\right)$ & \\
Total output & \\
$\mathbf{x}^{\prime}=\left(x_{j}\right)$ &
\end{tabular}

the intermittency of solar and wind power generation must be compensated using natural gas-fired power generation as a dispatchable power supply. As the introduction of solar and wind power generation facilities increases, the extent of thermal power generation will be low. As a result of this, the operation rate of thermal power plants will reduce and the generation cost will increase, despite the importance of dispatchable power supplies to compensate for the intermittency of renewable energy sources. Through model analysis, many researchers argue that it is important to implement carbon pricing in a close relationship with renewable energy subsidization and other energy policies in the EU (Egli and Lecuyer 2017; Faerber et al. 2018) and the US (Kaufman and Hines 2018; Deetjen et al. 2018; Woo et al. 2018). Many of these studies mention a new cost-benefit analysis method for power systems, such as capacity remuneration schemes, to prevent reductions in efficiency in dispatchable power supplies.

These previous studies searched for methods of constructing an optimal new power supply system by combining the carbon pricing mechanism with other policies. Regardless of its type, the new system will need to be accepted by consumers. However, there appears to be no research on consumer opinions of the new power system utilizing carbon pricing. In this paper, using input-output analysis, we aim to evaluate the effect of changes in the Japanese electric power operation system utilizing carbon pricing from the viewpoint of consumers.

\section{Methodology}

Figure 1 is a conceptual diagram of the input-output table which we use for analysis. It is a matrix which summarizes the annual transactions between sectors within an economy (Leontief 1986). The horizontal rows show how the output of each sector of the economy is distributed among the others. Conversely, the vertical columns show how 
each sector obtains from the others its needed inputs. This double-entry bookkeeping of an input-output table reveals interdependence of the economic sectors.

In Japan, the input-output table (basic table) is prepared by the Ministry of Internal Affairs and Communications (MIC) every five years. In Fig. 1, $x_{i j}$ is the component of intermediate transaction matrix, $\mathbf{X}$, and represents the monetary amount of the $i$-th good consumed by activity $j . \sum_{j} x_{i j}+f_{i}=x_{i}$ is the sum of intermediate demand of the $i$-th sector's good and the final demand, $f_{i}$, and it presents the total output for sector $i, x_{i}$. Similarly, $\sum_{i} x_{i j}+v_{j}=x_{j}$ is the sum of intermediate inputs to the $j$-th sector and the value added, $v_{j}$, and it presents the total output for sector $j, x_{j}$. The ratio of $x_{i j}$ to $x_{j}, a_{i j}=x_{i j} / x_{j}$ is called the input coefficient. Therefore, the following equation holds true.

$$
\sum_{i} a_{i j}+v_{j} / x_{j}=1 .
$$

A full set of input coefficients of all sectors is described by the symbol $\mathbf{A}$, and called the input coefficient matrix. Using an input coefficient matrix, we can express a demand and supply balance as follows.

$$
\mathbf{A x}+\mathbf{f}=\mathbf{x} .
$$

Here, $\mathbf{x}$ is the total output vector (in millions of JPY), $\mathbf{A}$ is the input coefficient matrix, and $\mathbf{f}$ is the vector of final demands (in millions of JPY). Solving Eq. (2) for $\mathbf{x}$, we can obtain a Leontief inverse matrix, $\mathbf{B}=(\mathbf{I}-\mathbf{A})^{-1}$. The elements of the $j$ th column of $\mathbf{B}$ indicate amounts of inputs necessary directly and indirectly for final demand of one unit of goods in sector $j$. That is, it shows not only the inputs necessary for direct production of the jth sector, but also all inputs required for the whole supply chain process of the $j$ th sector. When the $j$ th column of $\mathbf{B}$ is denoted by $\mathbf{B}_{j}$, by replacing $\mathbf{x}$ with $\mathbf{B}_{j}$ in Eq. (2), we obtain Eq. (3):

$$
\mathbf{A} \cdot \mathbf{B}_{j}+\mathbf{I}_{j}=\mathbf{B}_{j}
$$

where $\mathbf{I}_{j}$ is a column vector, which makes the $j$ th element 1 and the other zero. Here,

$$
\mathbf{U}_{j}=\mathbf{A} \cdot \mathbf{B}_{j} .
$$

is a concept defined as a unit structure of $j$ th sector by Ozaki (1980). This formula shows the trading structures of all intermediate goods and services that are directly and indirectly caused when one unit of the $j$ th good is produced. Ozaki interpreted this as a "production function", indicating structural inputs for one unit of $j$ th output.

Ozaki (1980) expanded Eq. (4) as follows:

$$
\overline{\mathbf{U}}_{j}=\mathbf{A} \cdot \widehat{\mathbf{B}}_{j}=\left[\begin{array}{ccc}
a_{11} & \cdots & a_{1 n} \\
\vdots & \ddots & \vdots \\
a_{n 1} & \cdots & a_{n n}
\end{array}\right] \cdot\left[\begin{array}{ccc}
b_{1 j} & \cdots & 0 \\
\vdots & \ddots & \vdots \\
0 & \cdots & b_{n j}
\end{array}\right]=\left[\begin{array}{ccc}
u_{11} & \cdots & u_{1 n} \\
\vdots & \ddots & \vdots \\
u_{n 1} & \cdots & u_{n n}
\end{array}\right] .
$$


Table 1 Assumed power supply composition ratio for 2030
Facility construction $(\%)$

Power generation (\%)

\begin{tabular}{lrr}
\hline Conventional power & & \\
Nuclear & 11.4 & 21.0 \\
Thermal & 45.2 & 56.0 \\
Hydro & 15.7 & 8.2 \\
Renewable energy power & & \\
Solar power for residential use & 3.0 & 0.9 \\
Solar power for business & 18.2 & 6.2 \\
Onshore wind & 3.0 & 1.5 \\
Offshore wind & 0.3 & 0.2 \\
Small and medium hydropower & 0.5 & 0.8 \\
Large geothermal & 0.4 & 0.8 \\
Hot spring binary & 0.1 & 0.2 \\
Woody biomass & 1.5 & 2.8 \\
Methane fermentation biomass & 0.1 & 0.1 \\
Waste (large-scale) & 0.3 & 0.6 \\
Waste (medium-scale) & 0.4 & 0.7 \\
Total & 100.0 & 100.0 \\
Renewable energy sub-total & 43.4 & 23.0
\end{tabular}

We developed an Input-Output Table for a Next Generation Energy System (IONGES) which incorporated renewable energy based on a table prepared by MIC (Nakano et al. 2017). ${ }^{3}$ The IONGES has two types of tables; one incorporates renewable energy sectors that existed in 2005 (2005 IONGES) and the other incorporates renewable energy sectors up to the composition ratio assumed for 2030 (2030 IONGES). The 2030 IONGES assumes that the power supply composition ratio (including renewable energy) improves until the government's goal for 2030 is reached, without changing the total number of power facilities constructed and electricity generated in 2005. Table 1 shows the types of power and their component ratios (facility composition and power generation composition) in 2030 IONGES. In IONGES, the average producer's price in the MIC input-output table is applied not only to existing power sources such as nuclear, thermal, and large-scale hydro, but also to renewable energy power sources. This method follows the single price principle adopted in the MIC input-output table. Under this assumption, the value of electricity can be easily converted to a physical quantity $(\mathrm{kWh})$ using the producer's price. However, electricity from renewable energy is actually purchased at a higher price than that of the producer under the feed in tariff (FIT) scheme. In IONGES, the difference between the purchaser's price and the producer's price is treated as a subsidy. In other words, the difference represents a deduction item in the value-added sector. Unlike the MIC input-output

\footnotetext{
3 This table is published at https://www.f.waseda.jp/washizu/table.html.
} 


\begin{tabular}{|c|c|c|c|c|c|c|c|}
\hline & \multirow{2}{*}{$\begin{array}{c}\text { Region } 1 \\
\text { Sector } 1 \cdots \text { Sector } n\end{array}$} & \multirow{2}{*}{$\begin{array}{c}\text { Region } 2 \\
\text { Sector } 1 \cdots \text { Sector } n\end{array}$} & \multirow{2}{*}{$\cdots \cdots$} & \multirow{2}{*}{$\begin{array}{c}\text { Region } 9 \\
\text { Sector } 1 \cdots \text { Sector } n\end{array}$} & \multirow{2}{*}{$\begin{array}{c}\text { Final } \\
\text { Demand }\end{array}$} & \multirow{2}{*}{$\begin{array}{c}\text { Total } \\
\text { Output }\end{array}$} \\
\hline & & & & & & & \\
\hline $\begin{array}{l}\text { Region } 1 \\
\text { Hokkaido }\end{array}$ & $\begin{array}{l}\text { Sector } 1 \\
\vdots \\
\text { Sector } n\end{array}$ & & & & & & \\
\hline $\begin{array}{l}\text { Region } 2 \\
\text { Tohoku }\end{array}$ & $\begin{array}{l}\text { Sector } 1 \\
\vdots \\
\text { Sector } n\end{array}$ & & & & & & \\
\hline $\begin{array}{l}\text { Region9 } \\
\text { Okinawa }\end{array}$ & $\begin{array}{l}\text { Sector } 1 \\
\dot{S} \\
\text { Sector } n\end{array}$ & & & & & & \\
\hline Value Adde & & & & & & & \\
\hline Total Outpu & & & & & & & \\
\hline
\end{tabular}

Fig. 2 Layout of the Inter-Regional IONGES used in this study

table, IONGES describes the output structure for each power source. However, the output structure for all power sources is assumed to be the same.

The 2030 IONGES was accompanied by an Inter-Regional IONGES based on a table prepared by the Ministry of Economy, Trade and Industry (METI) (Nakano and Washizu 2018). Figure 2 is a conceptual presentation of an Inter-Regional IONGES. The quantities of inputs and value added elements necessary for production in a sector in an area is recorded in the columns. In the horizontal direction, allocations by region and by sector of output in various sectors of the regions are shown in rows. This table enables analysis of the interdependency of regions and sectors (including renewable energy sectors). For example, the influence of economic activities in the Kanto region on the demand for electricity from renewable energy in the Hokkaido region is visualized.

Using the Inter-Regional IONGES, and considering the leakage of ripple effects due to imports, the Leontief inverse matrix, $\mathbf{B}=(\mathbf{I}-\mathbf{A})^{-1}$, is expanded as follows:

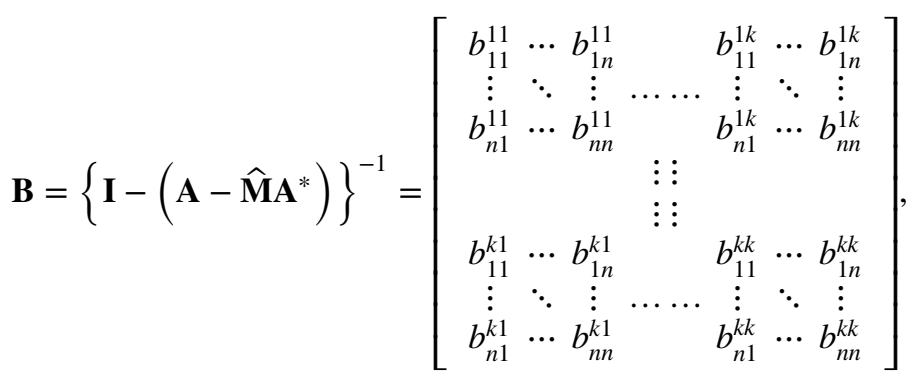

$b_{i j}^{g h}$ is production of the i sector in the $\mathrm{g}$ region induced by production of the $\mathrm{j}$ sector in the h region, $\mathbf{I}$ is identity matrix, $\mathbf{A}$ is inter-regional input coefficients matrix of the IONGES, $\hat{\mathbf{M}}=\left[m_{i j}^{* g}\right]$ is diagonal matrix of import coefficients, 
$\left(m_{i j}^{* g}=-m_{i}^{g} /\left(\sum_{l} x_{i l}^{g h}+f_{i}^{g h}\right)\right.$ when $g=h$ and $i=j$, and $m_{i j}^{* g}=0$ when $g \neq h$ or $\left.i \neq j\right)$, $\mathbf{A}^{*}=\left[a_{i j}^{* g h}\right]$ is block diagonal matrix of intra-regional input coefficients, $\left(a_{i j}^{* g h}=a_{i j}^{g h}\right.$ when $g=h$ and $a_{i j}^{* g h}=0$ when $g \neq h$ ).

Direct and indirect production induced by the consumption in a region was calculated as follows:

$$
\mathbf{x}^{g}=\left\{\mathbf{I}-\left(\mathbf{A}-\widehat{\mathbf{M}} \mathbf{A}^{*}\right)\right\}^{-1}(\mathbf{I}-\widehat{\mathbf{M}}) \mathbf{f}^{g},
$$

$\mathbf{x}^{g}$ is vector of the production induced by the consumption in region $g$ and, $\mathbf{f}^{g}$ is vector of the consumption in region $g(g=1 \ldots, k)$.

\section{Data: Inter-Regional Input-output Table for a Next Generation System (Inter-Regional IONGES)}

In our previous research (Nakano and Washizu 2018), we created the Inter-Regional IONGES by deploying the 2030 IONGES to regions based on the METI's interregional input-output table. We assumed that renewable energy power generation is distributed between regions in proportion to the distribution of resource reserves estimated by the MOE. In this study, we created the Inter-Regional IONGES ver. 2 by revising the following points of our previous research (Nakano and Washizu 2018). Hereafter, Inter-regional IONGES refers to Inter-regional IONGES ver. 2 unless otherwise stated.

1. Since our previous study (Nakano and Washizu 2018), the government's goal regarding power supply composition ratios for 2030 has been revised, so we updated our assumptions. That is, we revised the assumption to METI's "LongTerm Energy Supply and Demand Outlook" (July 2015).

2. Assumptions of the inter-regional distribution of renewable energy power generation were changed to those established by the Organization for Cross-regional Coordination of Transmission Operators, Japan (OCCTO), and the output suppression rate of solar and wind power generation was considered.

3. We set three different assumptions for the inter-regional transmission of renewable energy, and created Inter-Regional IONGES under each assumption.

To meet the format of the METI's inter-regional input-output table, our InterRegional IONGES has been divided into nine regions, Hokkaido, Tohoku, Kanto, Chubu, Kinki, Chugoku, Shikoku, Kyushu, and Okinawa, and each region is divided into 85 sectors, including 11 electric power facility construction and 11 power generation sectors considering the renewable energy types in Table 1.

The assumed value of the regional composition ratio of renewable energy established by OCCTO was used. For the variable power supply (solar/wind power), the power suppression rates estimated by the Working Group in General Resources and Energy Research Committee were considered. The expected future power suppression 


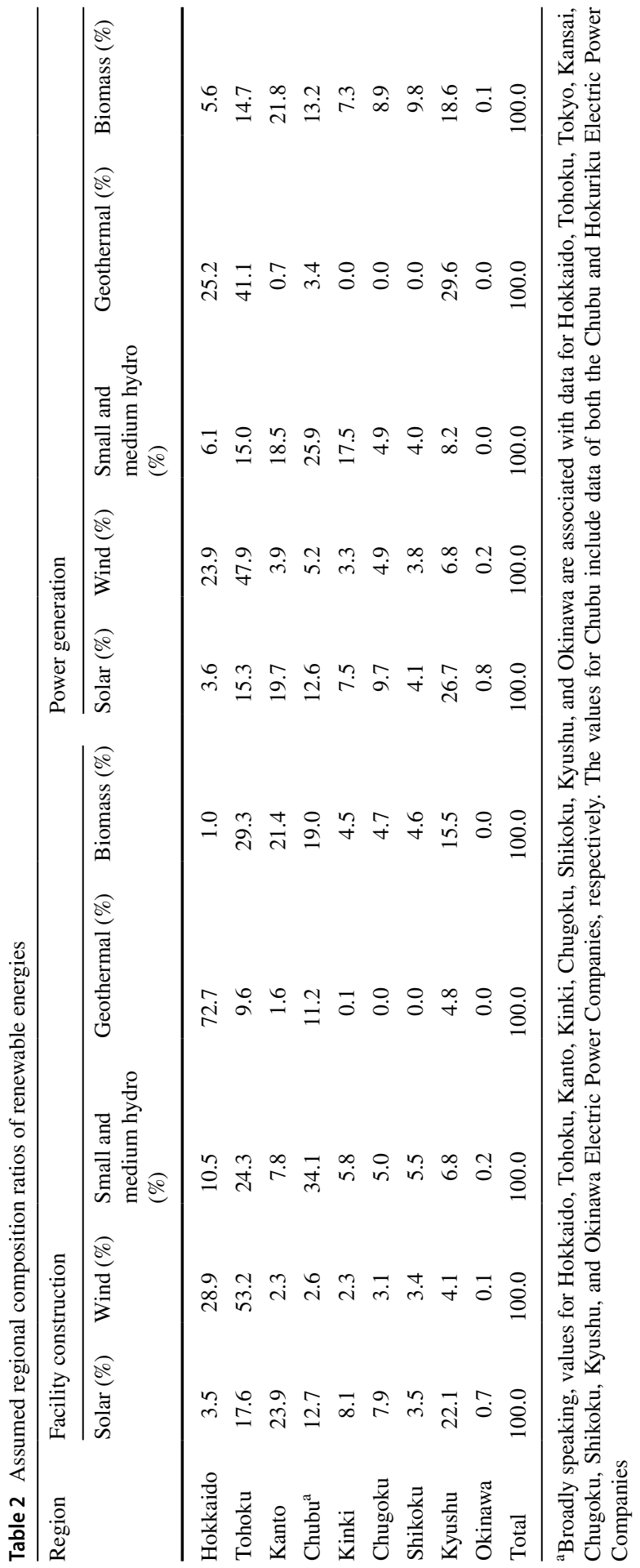


Fig. 3 Distribution of renewable energy generation by region from the Inter-Regional IONGES

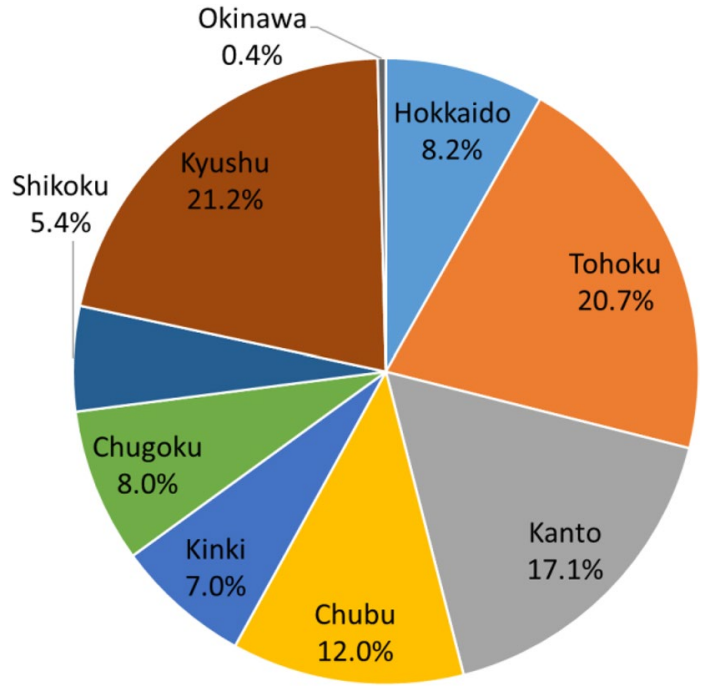

rate for solar power generation is $41.2 \%$ in Hokkaido, $40.7 \%$ in Tohoku, and $26.3 \%$ in Kyushu, while that for wind power generation is $27.8 \%$ in Hokkaido and $9.6 \%$ in Tohoku. There is no power suppression in Kanto, Chubu, or Kinki. Table 2 shows the regional distribution of each renewable energy type under these assumptions.

As mentioned above, the Japanese electric power system is divided into several regions, and the minimum amount of electricity necessary is interchanged among these regions. Under existing system operation rules, renewable energy is not an object of power interchange between regions. However, as a countermeasure to the intermittency of variable power supplies, it is thought that the wide-area operation of the electric power system should progress toward the future. Therefore, we created three Inter-Regional IONGES with different assumptions for inter-regional transmissions and verified the effects of the wide-area operation of the electric power system. We created IONGES' that were predicated on three assumptions for electric power interchange, including:

Case 1: The current situation in which renewable energy is not object to power interchange;

Case 2: Renewable energy is interchanged between regions at the same level as conventional power; and.

Case 3: The grids of Japan are linked and renewable energy and conventional power are fully interchangeable,

with increasing interchange from Case 1 to 3 . Case 3 assumes that all domestic power is pooled in one grid. Therefore the type of power supply in the output and input structures in each sector are uniform for all regions. 
Fig. 4 Distribution of renewable energy generation by region from the previous study (Nakano and Washizu 2018)

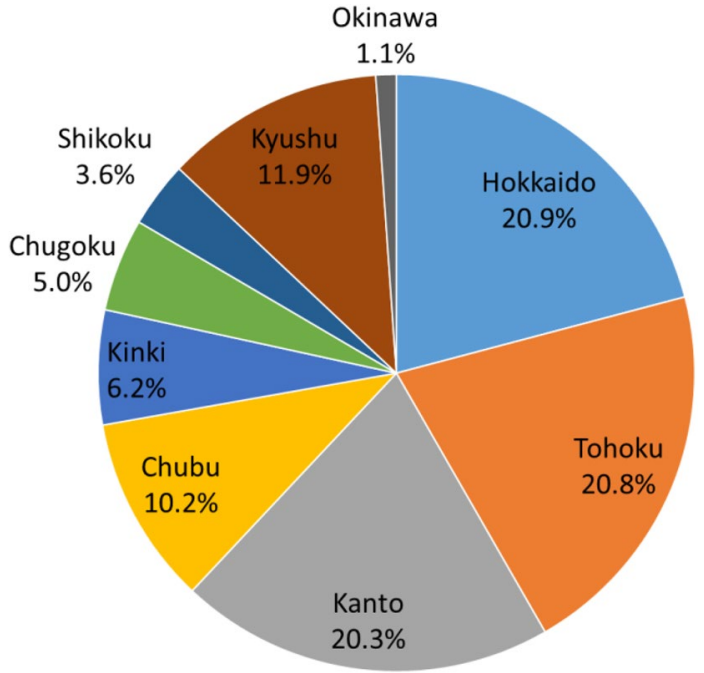

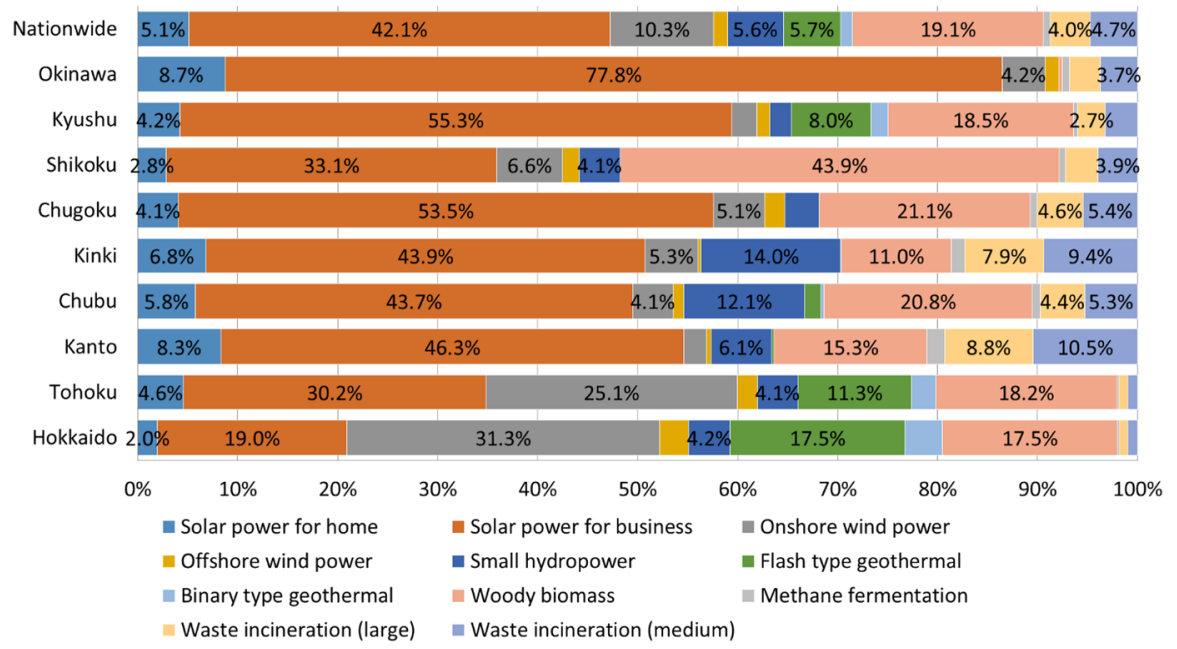

Fig. 5 Relative proportions of various types of renewable energy in the Inter-Regional IONGES

\section{Results}

\subsection{Regional distribution of renewable energy generation}

The distribution of renewable energy generation in 2030 by region according to the Inter-Regional IONGES is shown in Fig. 3, while the data from our previous study (Nakano and Washizu 2018) are shown in Fig. 4. In Fig. 3 (regional allocation results from OCCTO based on technical constraints), the total renewable energy proportion of Hokkaido is lower than that in Fig. 4 (regional allocation results based 


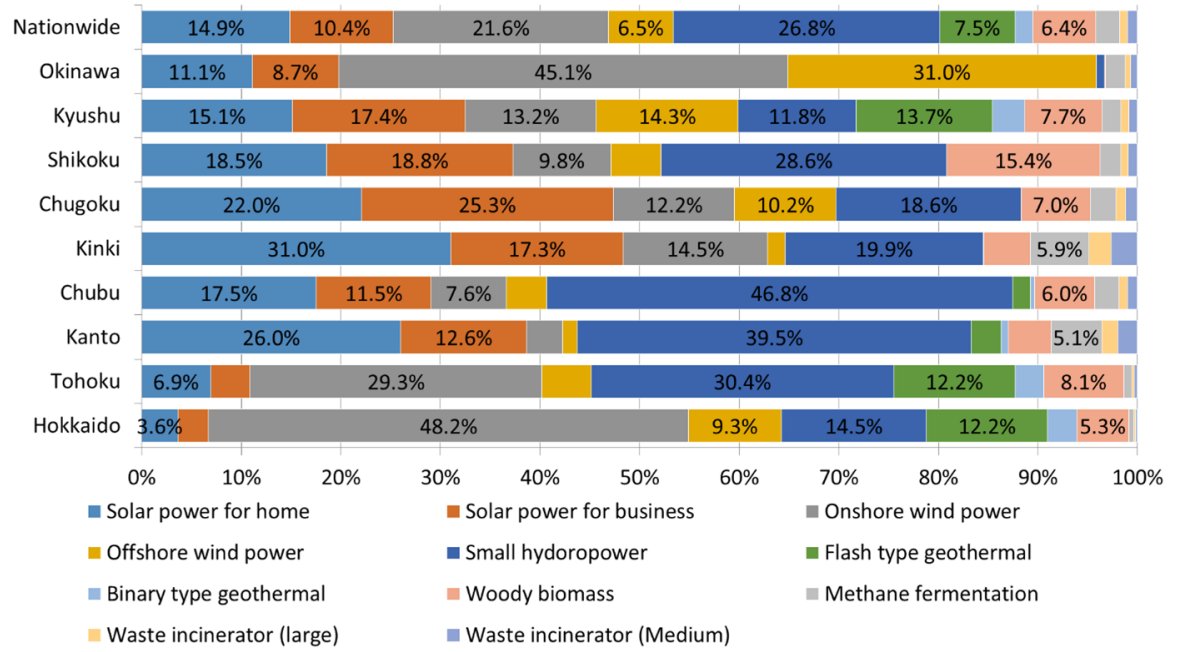

Fig. 6 Relative proportions of various types of renewable energy in the previous study (Nakano and Washizu 2018)

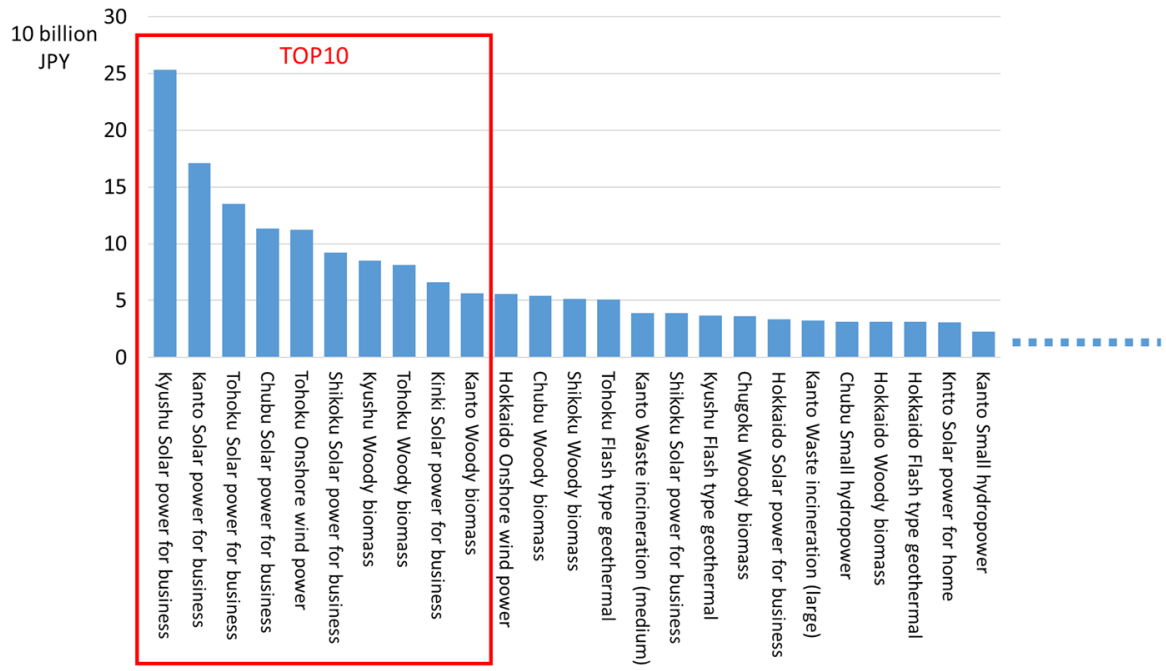

Fig. 7 Distribution of electricity production by region and renewable energy type

on the renewable energy potential in each region). However, the composition ratios of Kyushu will increase.

The proportion of renewable energy by energy type for each region is displayed in Fig. 5, and the same data from our previous study (Nakano and Washizu 2018) are shown in Fig. 6. The ratio of solar power generation in each region is higher in Fig. 5 than that in Fig. 6, but that of wind power generation decreases. Also, in some areas, the ratios of woody biomass and waste incinerator power generation are 


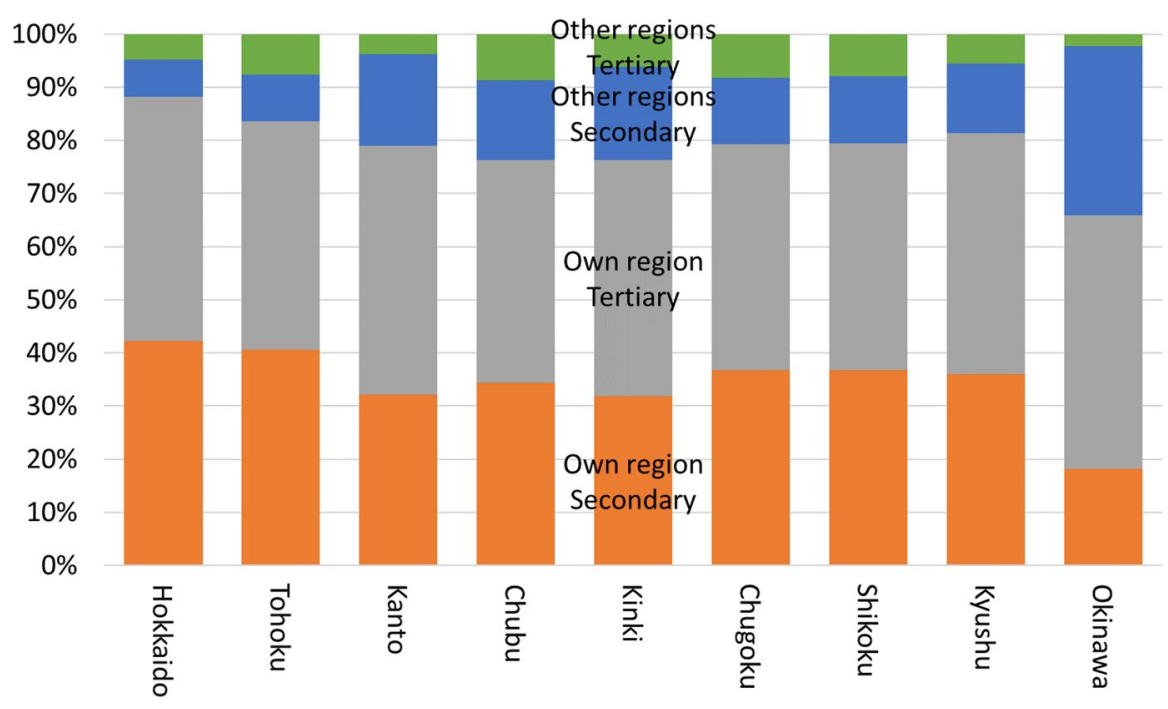

Fig. 8 Input composition of the woody biomass power generation sector in each region (Case 1)

increasing. These results demonstrate that output suppression due to technical constraints of the power grid greatly influences the inter-regional distribution of renewable energy. From the comparison of these figures, it can be seen that the power system constraints have greatly restricted the use of renewable energy resources, such as wind power, that are abundant in regions such as Hokkaido.

Figure 7 shows the distribution of electricity production by region and renewable energy type. The regional generation of the top ten sectors (TOP10), which have large production scales, accounts for approximately 54\% of renewable energy generation throughout Japan. The remaining $46 \%$ is divided among 82 regional renewable energy types. Figure 7 shows that the distribution of renewable energy in Japan favors a particular power source in a particular area.

\subsection{Input coefficients and unit structures of renewable energy sectors}

We created three Inter-Regional IONGESs for 2030 with different assumptions for electric power interchanges. The input composition ratio of the renewable energy power sector (the composition ratio of the column vectors of a renewable energy sector in the colored part of Fig. 2) differs between the three Inter-Regional IONGESs. Taking woody biomass power generation in each region as an example, we examined the effects that different assumptions for electric power interchanges have on input composition. In Figs. 8 and 9, the region is compiled into two areas, i.e., each own region and other regions, and the sector is aggregated into three sectors, i.e., primary, secondary, and tertiary. The tertiary industry includes wholesale and transportation, power transmission, repair, and information services. When interregion transmission becomes active from Case 1 to 3, every region will use more 


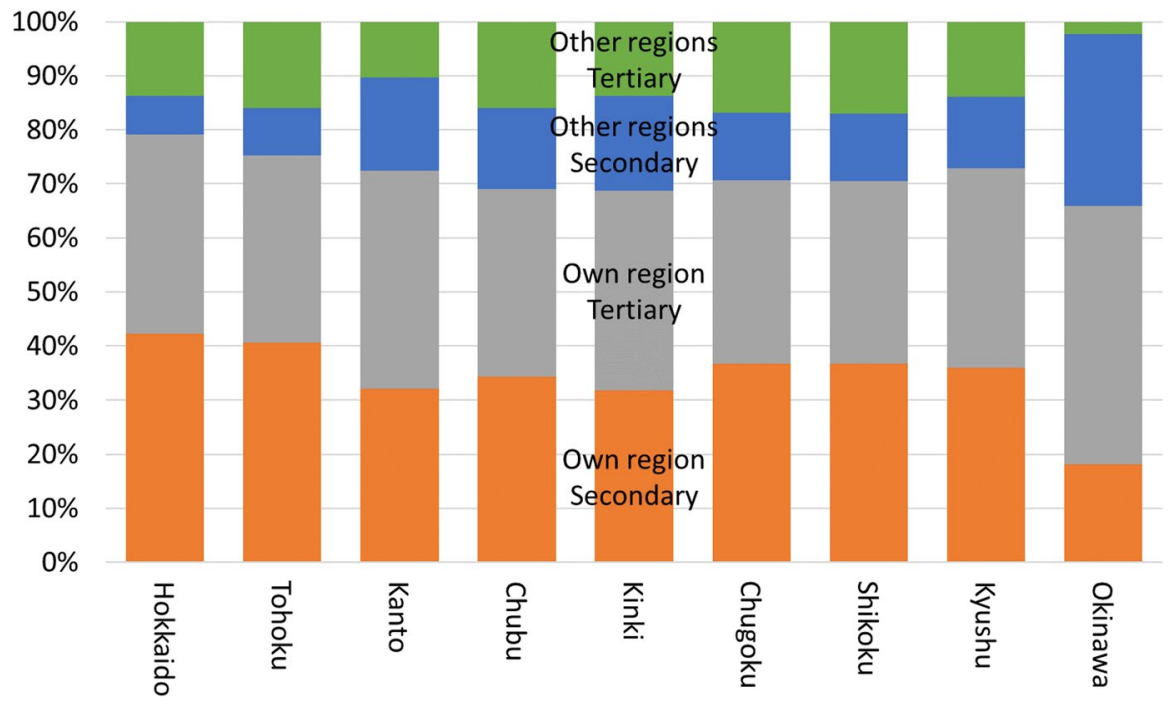

Fig. 9 Input composition of the woody biomass power generation sector in each region (Case 3)

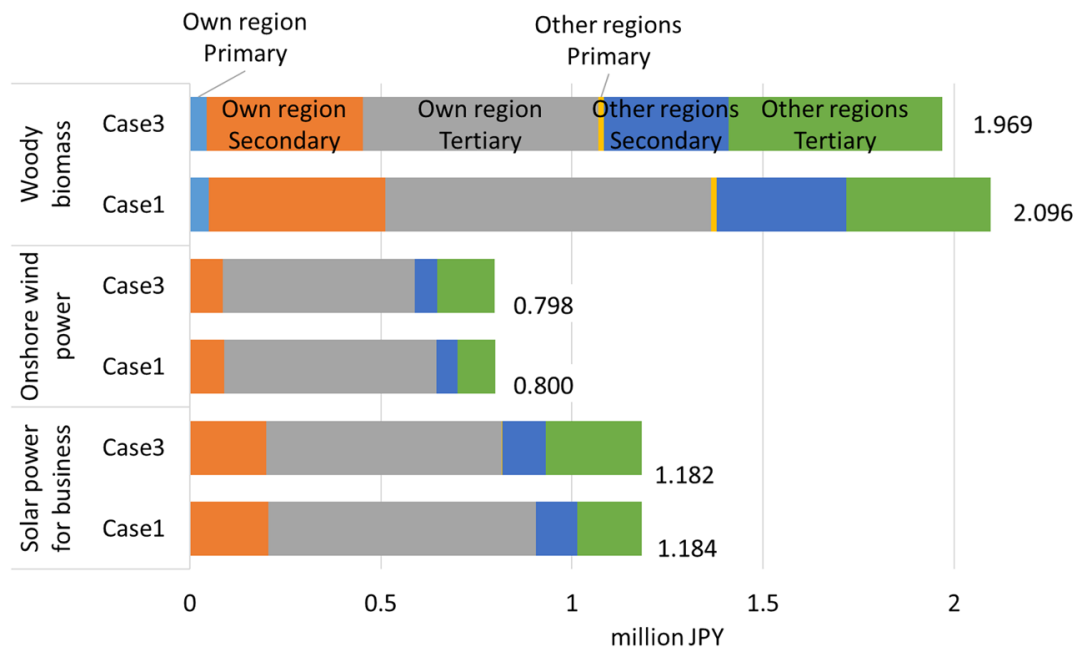

Fig. 10 Total elements of unit structure in Tohoku (the sum of direct and indirect intermediate inputs induced by one million JPY of generation activity)

power transmission services from other areas, so the input ratio of the tertiary industry from other regions will increase.

Figure 10 compares the total elements of unit structures of solar power for business, onshore wind power, and woody-biomass power generations in Tohoku. It was calculated by assigning the input coefficient matrix of Inter-Regional IONGES to $\mathbf{A}$ in Eq. (4) and substituting the $j$ th column of Eq. (6) into $\mathbf{B}_{j}$ in Eq. (4). The total 


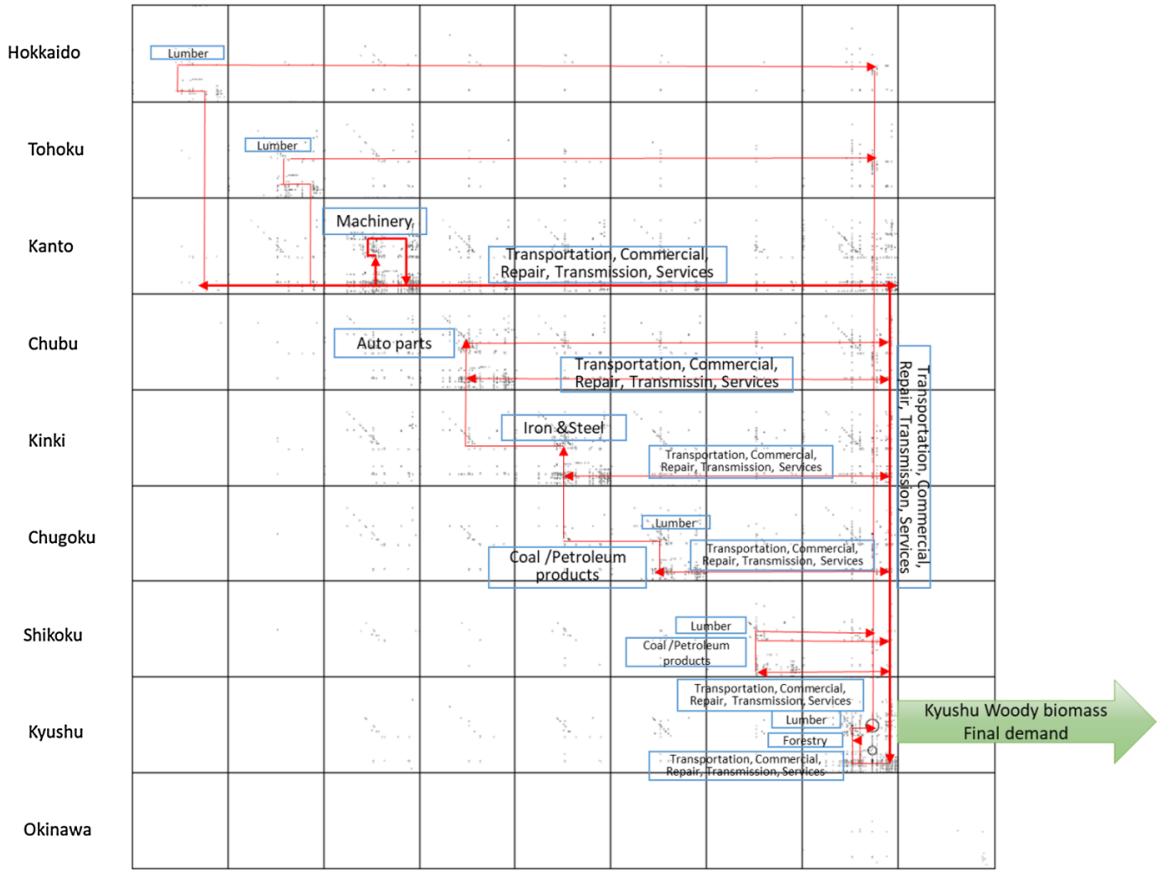

Fig. 11 Unit structure of the woody biomass power generation sector in Kyushu (Case 3)

elements of each unit structure show the sum of direct and indirect intermediate inputs induced by one unit of each generation activity. In other words, the sum indicates the unit cost of each power generation type. According to Fig. 10, the unit cost decreases slightly from Case 1 to Case 3 due to the wide operation area of electric power. We concluded that this happens because the use of a wide operation area results in a power transmission service with low cost. In addition, among the three power generating activities shown in Fig. 10, the unit cost of onshore wind power is the smallest, and that of woody biomass is the highest. However, the production and transportation of biomass fuel, which is an expensive aspect of woody biomass power generation, may bring business opportunities to rural areas that lack such opportunities.

Figure 11 shows the distribution of each unit structure element from Kyushu's woody-biomass power generation. The dots in the figure indicate that a transaction of intermediate goods from the regional sector in the horizontal direction to the regional sector in the vertical direction is being triggered. Figure 11 shows that Kyushu-woody-biomass power generation triggers production activities in the geographically distant regions of Hokkaido and Tohoku. Commercial margin and information service transactions accompanying power transmission will occur in each region when the power grid is operated over a wide area and power is actively transmitted between regions. As a result, interdependent relationships between regions will deepen. Figure 11 shows this deepened inter-regional interdependency under the assumptions of Case 3. In addition, from Fig. 11, it can be confirmed that the 


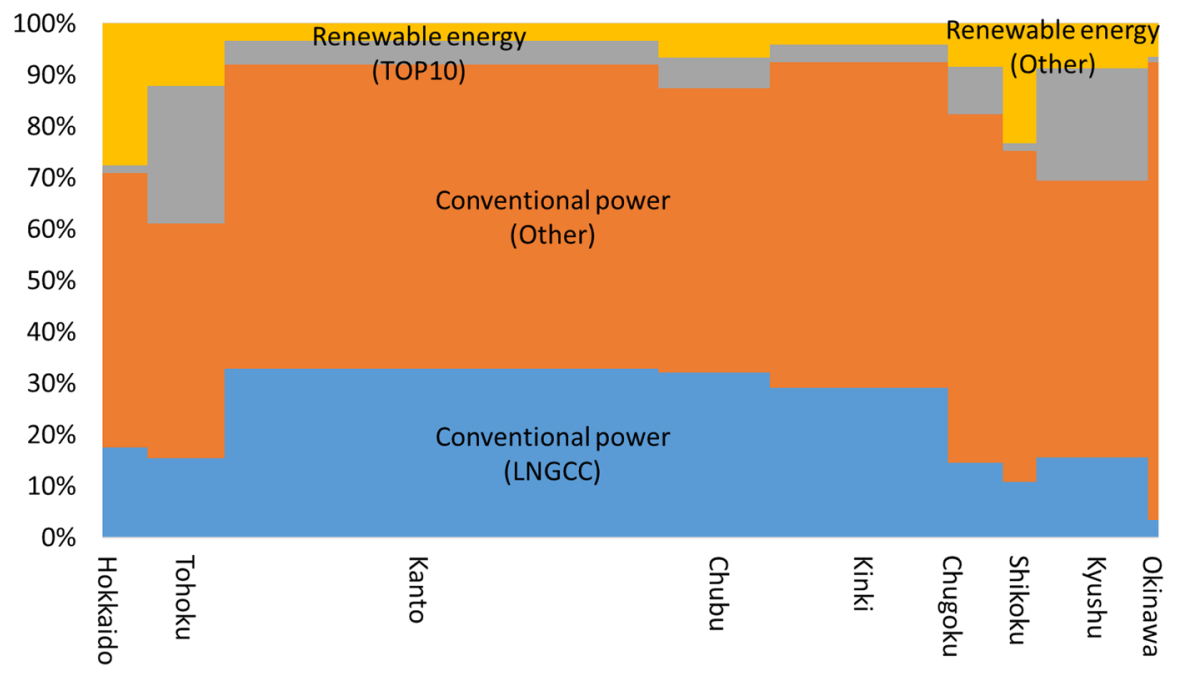

Fig. 12 Induced electricity demand (Case 1)

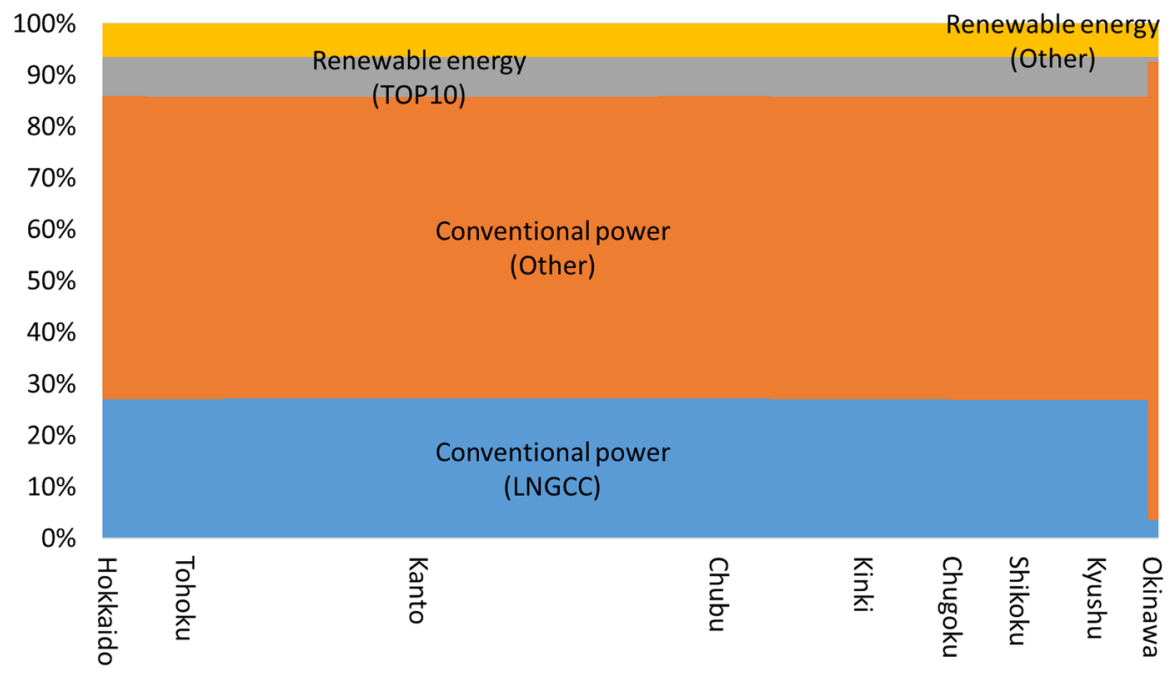

Fig. 13 Induced electricity demand (Case 3)

production of automobile parts to repair vehicles that transport biomass fuel and their gasoline consumption increase in areas where automobile and petroleum refining industries are concentrated.

\subsection{Electricity demand induced by consumption in each region}

Using Eq. (7), we calculated the electricity costs necessary to meet consumption demand by region and the results are shown in Figs. 12 and 13. The size of private 


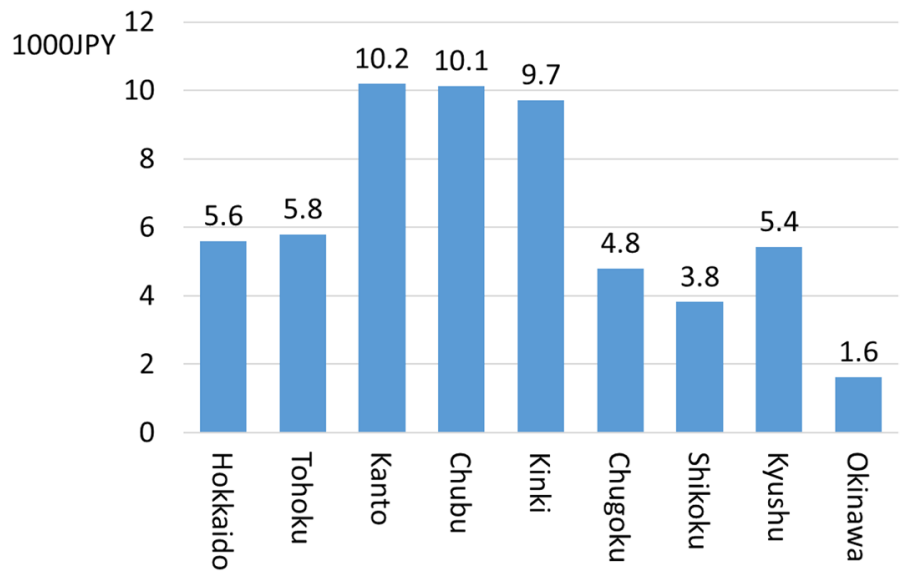

Fig. 14 Electric power costs by LNGCC to meet 1 million JPY of consumption in each region (Case 1)

consumption in each region is displayed on the $x$-axis while the $y$-axis represents the proportion by power source of the electricity cost necessary to meet total consumption demand for each region. Each area in the figures shows the total cost for various power sources required for total consumption in each region.

The induced electricity costs were separated into renewable energy (TOP10 renewable energy sectors and others) and conventional power [LNG combined cycle thermal power generation (LNGCC) and others]. TOP10 renewable energy sectors are the types of regional renewable energy shown in Fig. 7. LNGCC was considered separately because of the attention it is receiving as a dispatchable power source and a low-carbon power source with the diminishing public interest in nuclear power. LNGCC is an excellent power source with high generation efficiency. Based on the capacity of each electric power company and power supply proportion (e.g. $\mathrm{LNG}=27 \%$ ) in the long-term energy supply-demand outlook, the ratios of conventional power supply from LNGCC to other conventional power sources are as follows: Hokkaido 21.5\%, Tohoku 22.0\%, Kanto 38.4\%, Chubu 39.5\%, Kinki 32.3\%, Chugoku 12.9\%, Shikoku 8.7\%, and Kyushu $19.5 \%$.

The expansion of the power system from Case 1 to 3 results in a homogenous mixture in the electricity cost induced by consumption in each region. This implies that the benefits from efficiency improvement for the TOP10 renewable energy sectors and LNGCC power achieved due to policy reforms will be distributed equally across the country. An expanded electricity supply network will ensure equitable effects for improved efficiency of the electricity supply in residents nationwide.

\section{Discussions}

Using the result presented in Fig. 12 (Case 1), we calculated the induced power cost per million yen of consumption in each region. The results are shown in Figs. 14 and 15. 


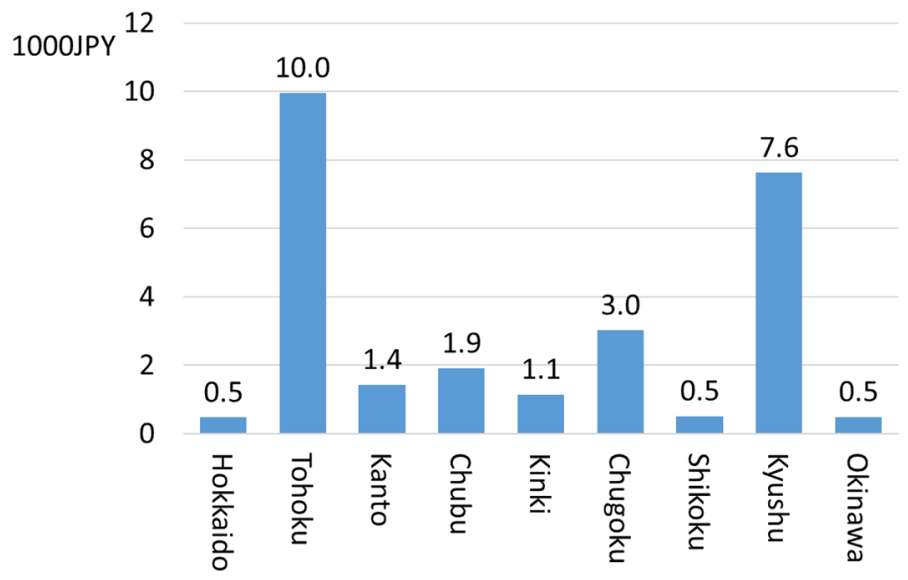

Fig. 15 Electric power costs by the TOP10 renewable energy sectors to meet 1 million JPY of consumption in each region (Case 1)

According to Fig. 14, the LNGCC power used for one million yen of consumption in Kanto is 10.2 thousand JPY, while that of Shikoku is 3.8 thousand JPY. The usage level of LNGCC electricity in Shikoku is $37 \%$ of that of Kanto. The power generation efficiency of LNGCC is high, and the $\mathrm{CO}_{2}$ emission intensity per $\mathrm{kWh}$ of LNGCC electricity is lower than that of other dispatchable thermal power generation types. When carbon pricing mechanisms are introduced into the electricity market, low-carbon electricity like LNGCC will be more economical than other thermal electricity types such as coal-fired electricity. As the result, consumers in Shikoku may be more susceptible to an increase in electricity prices than those in the Kanto region. If the electricity cost required for consumption in each region is leveled, as shown in Fig. 13 (Case 3), the introduction of a carbon pricing mechanism will equally impact regional consumers.

According to Fig. 15, the TOP10 renewable energy sectors generated 10.0 thousand JPY of the electricity required for one million yen of consumption in Tohoku, while they generated 0.5 thousand JPY in Shikoku. The usage level of electricity from the TOP10 sectors in Shikoku is only $5 \%$ that of Tohoku. IEA and NEA (2015) reported that the renewable energy generation costs are higher in Japan than those in other countries. Therefore, in Japan, it is necessary to invest in technological development and reform the social system to reduce the renewable energy generation cost. It is reasonable that such investment and reforms first target regional renewable energy types with large power generation scales, such as the TOP10 sectors. Even the MOE's "Study group on the way of carbon pricing" report published in March 2018 reports that a distinction should be made between policies for large and small businesses to achieve reliable results. If renewable energy generation cost reduction policies focus on large-scale renewable energy sectors, such as the TOP10, the policy effect is unequally distributed among consumers in each region according to Fig. 15. If the electricity cost required for consumption in each region is leveled, as shown in Fig. 13 (Case 


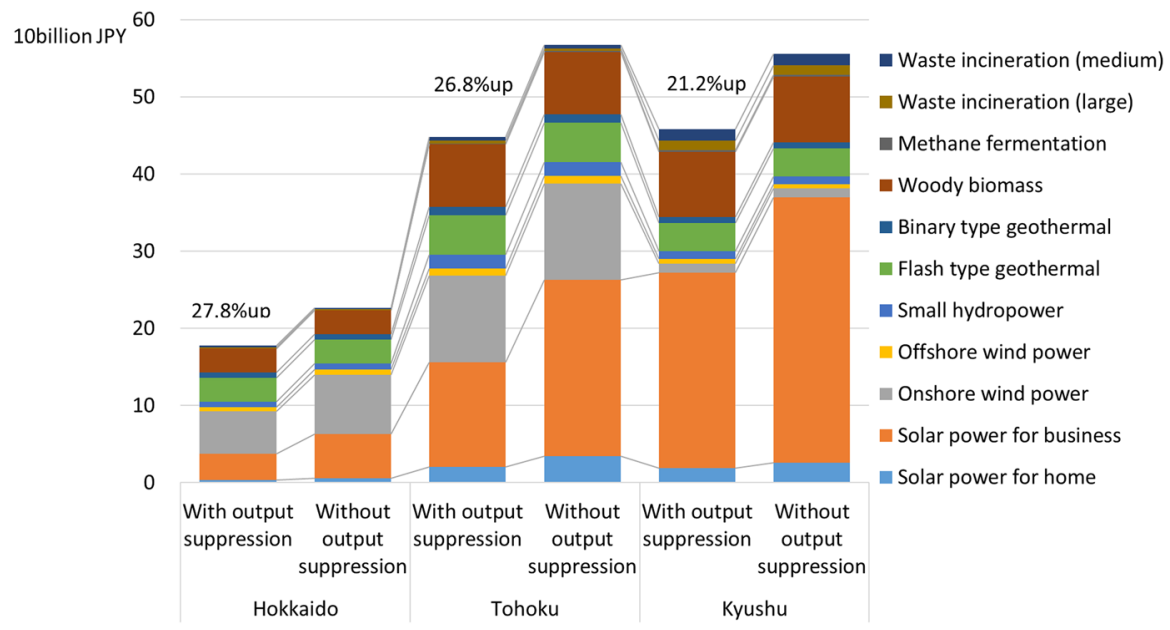

Fig. 16 Increase in renewable energy with and without output suppression

3), the renewable energy generation cost reduction policy will equally impact regional consumers.

As mentioned above, the widening of the power grid is an effective method to prevent the suppression of outputs from variable power sources, such as solar and wind power. The Inter-Regional IONGES adopted output suppression for solar power in Hokkaido, Tohoku, and Kyushu, and wind power in Hokkaido and Tohoku following the OCCTO considerations. We calculated the increase in renewable energy amounts without suppression of the output for solar and wind power for these regions. Figure 16 indicates that the total renewable power generation amounts increased by $21.2-27.8 \%$ in each region. Overall, renewable energy generation increased by $12.3 \%$ in Japan. Large costs will be necessary for widening the power grid, and it is necessary to strengthen transmission lines and frequency conversion devices between areas. However, technical options for reducing the output suppression of variable power sources are currently expanding, such as the development of various levels of energy management systems (EMS), utilization of storage batteries, electrolytic hydrogen, heat pump water heaters, and electric vehicles. To determine an optimal combination of these various technical options, a social cost-benefit analysis of technical options using our InterRegional IONGES should be conducted, and this is our future analysis subject. As discussed in Fig. 13, it would be essential to check the fairness of the burden and benefits from the consumer's point of view. Also, fairness for consumers, as shown in Fig. 13, could be achieved by establishing a financial trading system, namely the creation of a trading market for green certificates without physical power transmission. In Japan, such trading market, that securitizes the value of electricity from renewable energy, is not mature yet. With these considerations, the carbon pricing mechanism should be designed to efficiently implement not only the technical but also the institutional options for fairness to consumers. 


\section{Conclusions}

In this study, we examine the socioeconomic impact of carbon pricing mechanism-related energy policies under the technical constraints of renewable energy introduction in Japan. For this, we created the Inter-Regional IONGES for 2030 based on the long-term energy supply-demand outlook and assumptions for the regional allocation of renewable energy considering technical constraints. Namely, we have created three Inter-Regional IONGESs with different assumptions for the wide-area operation of the power grid.

The results of analysis using the Inter-Regional IONGES show that the technical constraints of the power grid influence the interregional distribution of renewable energy. The TOP10 sectors out of eleven renewable energy types by nine regions account for approximately $54 \%$ of renewable energy generation, and power generation was found to be biased towards a specific type of renewable energy in specific regions.

From considering the effects of the wide area operation of the power grid, it became clear that interdependence between the regional production activities that depend on the power generation sectors is deepened as the wide-area operation of the power grid proceeds.

As Japan's renewable energy costs are higher than those in other countries, it is expected that technological development and social system reform will reduce such costs. It is reasonable to apply such countermeasures for cost reduction to large-scale regional renewable energy types, such as the TOP10.

From the viewpoint of consumers in each region, we analyzed the shares of the electricity cost directly and indirectly required to meet their consumption demand. It was found that, under the current technical constraints of the power grid, there was a large variation in the power supply composition ratio that consumers in each region directly and indirectly depend on. The dependence rate on a low-carbon power supply, such as LNGCC, in a certain area is $37 \%$ of that of the other areas, whereas the dependence rate on renewable energy power sources that are expected to face future cost reductions, such as the TOP10 sectors, in a certain area is only $5 \%$ of that of other areas. Therefore, if the carbon pricing mechanism is implemented under the current technical constraints of the power grid, unequal impacts will be exerted on consumers in each region. However, it was that such inequality will be solved under wide-area power grid operation.

The wide-area power grid operation solves the unequal impact of carbon pricing on consumers due to the uneven distribution of renewable energy and efficient thermal power generators (such as LNGCC). In contrast, a large amount of additional investment will be required for transmission and distribution facilities for wide-area power grid operations. A limitation of this study is that it does not consider the large cost burden of this investment; however, a green power certificate market is expected to help mitigate the burden of these costs. If funding is provided for low-carbon electricity (such as renewable energy and LNGCC electricity) through green power certificate trading, investments will likely be promoted for facilities to improve the utilization rate of these electric power plants. 
Low-carbon power providers (such as renewable energy and LNGCC operators) funded by selling green certificates would try to sell as much clean power as possible using methods that are less expensive than constructing transmission and distribution facilities, such as using demand response, EV charging, and hydrogen. In Japan, the green power certificate market is not yet popular. However, in some areas of Japan, there are cases where emissions trading systems, including the green power certificate market, have been utilized, successfully reducing $\mathrm{CO}_{2}$ emissions (Arimura and Abe 2019; Hamamoto 2019). If such a system, which is currently operating regionally, was used nationwide, it would be possible to simultaneously have a low-carbon electricity system and fairness in respect to the consumer carbon tax burden. In the future, we will use the Inter-Regional IONGES to assess an institutional design of carbon pricing mechanism that can simultaneously address the issues related to low-carbon power systems and consumer burden.

Acknowledgements This study benefited from a MEXT Grant-in-Aid for Scientific Research (15KT0121, 16K12663), 2016-2018, and a Waseda University Grant for Special Research Projects (2019C-308), and a MOE Environment Research and Technology Development Fund (2-1707) of the Environmental Restoration and Conservation Agency.

Open Access This article is licensed under a Creative Commons Attribution 4.0 International License, which permits use, sharing, adaptation, distribution and reproduction in any medium or format, as long as you give appropriate credit to the original author(s) and the source, provide a link to the Creative Commons licence, and indicate if changes were made. The images or other third party material in this article are included in the article's Creative Commons licence, unless indicated otherwise in a credit line to the material. If material is not included in the article's Creative Commons licence and your intended use is not permitted by statutory regulation or exceeds the permitted use, you will need to obtain permission directly from the copyright holder. To view a copy of this licence, visit http://creativecommons.org/licen ses/by/4.0/.

\section{References}

Arimura TH, Abe T (2019) The impact of the Tokyo Emissions Trading Scheme on office buildings: what factor contributed to the emission reduction? No. 1908. Research Institute for Environmental Economics and Management, Waseda University

Deetjen TA, Martin H, Rhodes JD, Webber ME (2018) Modeling the optimal mix and location of wind and solar with transmission and carbon pricing considerations. Renew Energy 120:35-50. https:// doi.org/10.1016/j.renene.2017.12.059

Egli P, Lecuyer O (2017) Quantifying the net cost of a carbon price floor in Germany. Energy Policy 109:685-693. https://doi.org/10.1016/j.enpol.2017.07.035

Faerber LA, Balta-Ozkan N, Connor PM (2018) Innovative network pricing to support the transition to a smart grid in a low-carbon economy. Energy Policy 116:210-219. https://doi.org/10.1016/j.enpol .2018 .02 .010

Fan JH, Todorova N (2017) Dynamics of China's carbon prices in the pilot trading phase. Appl Energy 208:1452-1467. https://doi.org/10.1016/j.apenergy.2017.09.007

Gavard C (2016) Carbon price and wind power support in Denmark. Energy Policy 92:455-467. https:// doi.org/10.1016/j.enpol.2016.01.031

Guo Z, Ma L, Liu P, Jones I, Li Z (2017) A long-term multi-region load-dispatch model based on grid structures for the optimal planning of China's power sector. Comput Chem Eng 102:52-63. https:// doi.org/10.1016/j.compchemeng.2016.06.017 
Hamamoto M (2019) Impact of the Saitama Prefecture Target-Setting Emissions Trading Program on the Adoption of Low-Carbon Technology. Waseda University Research Institute for Environmental Economics and Management Discussion Paper

International Energy Agency (IEA) (2017) World energy balances 2017 edition. https://webstore.iea.org/ world-energy-balances-2017

International Energy Agency (IEA) and Nuclear Energy Agency (NEA) (2015) Projected costs of generating electricity 2015 edition. https://www.iea.org/Textbase/npsum/ElecCost2015SUM.pdf

Kaufmann RK, Hines E (2018) The effects of combined-cycle generation and hydraulic fracturing on the price for coal, oil, and natural gas: implications for carbon taxes. Energy Policy 118:603-611. https ://doi.org/10.1016/j.enpol.2018.03.039

Khan I (2018) Importance of GHG emissions assessment in the electricity grid expansion towards a lowcarbon future: a time-varying carbon intensity approach. J Clean Prod 196:1587-1599. https://doi. org/10.1016/j.jclepro.2018.06.162

Leontief W (1986) Input-output economics. Oxford University Press, New York

Li Y, Lukszo Z, Weijnen M (2015) The implications of $\mathrm{CO}_{2}$ price for China's power sector decarbonization. Appl Energy 146:53-64. https://doi.org/10.1016/j.apenergy.2015.01.105

Li Y, Lukszo Z, Weijnen M (2016) The impact of inter-regional transmission grid expansion on China's power sector decarbonization. Appl Energy 183:853-873. https://doi.org/10.1016/j.apenergy.2016.09.006

Liu Q, Zheng X, Zhao X, Chen Y, Lugovoy O (2018) Carbon emission scenarios of China's power sector: impact of controlling measures and carbon pricing mechanism. Adv Clim Change Res 9(1):27-33. https://doi.org/10.1016/j.accre.2018.01.002

Lyseng B, Rowe A, Wild P, English J, Niet T, Pitt L (2016) Decarbonising the Alberta power system with carbon pricing. Energy Strat Rev 10:40-52. https://doi.org/10.1016/j.esr.2016.05.001

Ma C, Ren Y, Zhang Y, Sharp B (2018) The allocation of carbon emission quotas to five major power generation corporations in China. J Clean Prod 189:1-12. https://doi.org/10.1016/j.jclepro.2018.04.006

Maryniak P, Truck S, Weron R (2019) Carbon pricing and electricity markets - the case of the Australian Clean Energy Bill. Energy Econ 79:45-58. https://doi.org/10.1016/j.eneco.2018.06.003

Nakano S, Arai S, Washizu A (2017) Economic impacts of Japan's renewable energy sector and the feedin tariff system: using an input-output table to analyze a next-generation energy system. Environ Econ Policy Stud 19(3):555-580. https://doi.org/10.1007/s10018-016-0158-1

Nakano S, Washizu A (2018) Development and application of an Inter-Regional Input-Output Table for analysis of a Next Generation Energy System. Renew Sustain Energy Rev 82:2834-2842. https:// doi.org/10.1016/j.rser.2017.10.011

Ohashi H (2015) Challenges posed by the full liberalization of the electricity market: Japan must find ways to ensure a stable power supply, February 26, 2016 Nihon Keizai Shimbun. https://www.rieti .go.jp/en/papers/contribution/ohashi/10.html. Accessed 19 Aug 2018

Ozaki I (1980) Structural analysis of economic development (3): determining the unit structure of the economy. Mita J Econ 73(5):66-94 (in Japanese)

Tian L, Pan J, Du R, Li W, Zhen Z, Qibing G (2017) The valuation of photovoltaic power generation under carbon market linkage based on real options. Appl Energy 201:354-362. https://doi. org/10.1016/j.apenergy.2016.12.092

Tu Q, Mo J (2017) Coordinating carbon pricing policy and renewable energy policy with a case study in China. Comput Ind Eng 113:294-304. https://doi.org/10.1016/j.cie.2017.09.026

Tu Q, Betz R, Mo J, Fan Y, Liu Y (2018) Can carbon pricing support onshore wind power development in China? An assessment based on a large sample project dataset. J Clean Prod 198:24-36. https:// doi.org/10.1016/j.jclepro.2018.06.292

United Nations (UN) (2011) Demographic yearbook-Table 3: population by sex, rate of population increase, surface area and density. https:/unstats.un.org/unsd/demographic/products/dyb/dyb2011/ Table03.pdf. Accessed 19 Aug 2018

Woo CK, Chen Y, Zarnikau J, Olson A, Moore J, Ho T (2018) Carbon trading's impact on California's realtime electricity market prices. Energy 159:579-587. https://doi.org/10.1016/j.energy.2018.06.188

Zhao Y, Li H, Xiao Y, Liu Y, Cao Y, Zhang Z, Wang S, Zhang Y, Ahmad A (2018) Scenario analysis of the carbon pricing policy in China's power sector through 2050: based on an improved CGE model. Ecol Ind 85:352-366. https://doi.org/10.1016/j.ecolind.2017.10.028

Publisher's Note Springer Nature remains neutral with regard to jurisdictional claims in published maps and institutional affiliations. 